\title{
Family Planning Awareness, Perceptions and Practice among Community Members in the Kintampo Districts of Ghana
}

Obed Ernest A. Nettey1, Yeetey A. Enuameh",2, Emmanuel Mahama1, Abubakari Sulemana1, George Adjei ${ }^{1}$, Stephaney Gyaase ${ }^{1}$, Samuel Afari-Asiedu' ${ }^{1}$, Robert Adda ${ }^{1}$, Abena Konadu Yawson', Gifty Fosuaa Nuamah1, Edward Apraku Anane1, Livesy Abokyi1, Charles Zandoh'1, Martha Abdulai' ${ }^{1}$, Ellen Abrafi Boamah ${ }^{1}$, Kwame Adjei, Seeba Amenga-Etego', Francis Dzabeng1, Charlotte Tawiah-Agyeman'1, Frank Baiden1, Kwaku Poku Asante1, Seth Owusu-Agyei ${ }^{1}$

${ }^{1}$ Kintampo Health Research Centre, Kintampo, Ghana

${ }^{2}$ Drexel University School of Public Health, Philadelphia, USA

Email: ernest.nettey@kintampo-hrc.org

Received 24 December 2014; accepted 22 January 2015; published 30 January 2015

Copyright (C) 2015 by authors and Scientific Research Publishing Inc.

This work is licensed under the Creative Commons Attribution International License (CC BY). http://creativecommons.org/licenses/by/4.0/

(c) (i) Open Access

\section{Abstract}

Family planning is known to prevent maternal deaths, but some social norms, limited supplies and inconsistent use makes this difficult to achieve in most low- and middle-income countries. In spite of the high fertility levels in most sub-Saharan African countries and the potential economic benefits of family planning, its patronage remains very low in the sub-region. This study was with the objective of identifying the levels of awareness, utilization, access to and perceptions about family planning and contraception. A cross-sectional study design was used for the study, with data collected from multiple sources using both quantitative and qualitative approaches. Relevant findings included a marked disconnect between family planning/contraceptive knowledge and use. The pills and injectables were the most frequently used, but females in the study population poorly patronised emergency contraception. Supplies of most family planning methods were found to be health facility based, requiring clients to have to necessarily go there for services. Some respondents harboured perceptions that family planning was the responsibility of females alone and that it fuelled promiscuity among female users. Recommendations made include ensuring that health facilities had adequate staff and expertise to provide facility-based family planning services and also to disabuse the minds of community members of the negative perceptions towards family planning. 


\section{Keywords}

\section{Family Planning, Contraception, Reproductive Health, Kintampo, Ghana}

\section{Introduction}

The United Nations estimates that the population of the world increased from 2.5 to 7 billion between 1950 and 2011 [1]. Fertility and future projected population growth are much higher in sub-Saharan Africa than in any other region of the world; furthermore, the population growth rate is of major international concern because it has the potential to hinder attainment of health and other development goals in the sub-region [2].

Family planning (FP) aims at empowering individuals and couples to anticipate and attain their desired number of children whilst appropriately spacing and timing their births. FP can prevent between $20 \%$ and $35 \%$ of maternal deaths, but social norms and limited FP supplies prevent correct and consistent FP use in most low- and middle-income countries [2].

In Ghana, FP uptake has not kept pace with the targets of national population policy adopted in 1969 and 1994 [3]. There was a rapid increase in contraceptive use from $12.9 \%$ in 1988 to $25.2 \%$ in 2003, and since then contraceptive use has not significantly changed [4]. The area of FP is a high interest to policy makers in Ghana as such quite a number of studies have been performed in this area. Research in this area has however been focused mostly on females and for that matter married females. Findings from some of these studies describe contraceptive use, attitudes towards FP and constraints associated with their use [5]-[8]. Most of these studies have also been cross-sectional i.e. performed at one point in time. The current study has focused on a wider population including adolescents, as well as bridging the gender gap by involving male partners of females. The paucity of longitudinal data to facilitate the understanding of the social dynamics of FP intentions and choices is a major drawback to the development of the next generation of FP interventions, which is particularly important for developing countries like Ghana.

The Kintampo Health and Demographic Surveillance System (KHDSS) of the Kintampo Health Research Centre (KHRC), located in the two Kintampo districts of central Ghana [9] is among a few sites in sub-Saharan Africa where population, health and social dynamics are continuously monitored over time. A FP survey was conducted from July 2011 to December 2011 as part of a larger Sexual and Reproductive Health (SRH) study, with the objective of identifying relevant FP indicators of the population covered by the KHDSS. Of particular interest were levels of FP awareness and use, access to FP and perceptions about FP and contraception. Data from this survey serves as a baseline to future surveys that will be conducted to document the FP dynamics over time.

\section{Methods}

A cross-sectional survey was conducted among women aged 15 - 49 years and where applicable, their partners. Both quantitative and qualitative methods were used.

\subsection{Study Area}

The survey was conducted in the core study area of KHRC, i.e. Kintampo North and South Districts. The area is largely rural with the district capitals, Kintampo and Jema assuming the status of an increasing population as observed in recent times, thus meriting semi-urban characteristics. As at December 2009, the total resident population was 134,970 with a total fertility rate (TFR) of 4.7 [9]. There were 32 neonatal deaths for every 1000 live births and infant mortality rate of approximately 52 deaths per 1000 live births. Average life expectancy at birth for both sexes was 60 years in 2009 with females living approximately 2 years longer than males [9].

\subsection{Survey}

A structured, closed-ended questionnaire was used; which enquired into respondents' reproductive history, knowledge and use of contraceptive as well as fertility preferences. To be able to capture their contraceptive/FP awareness and needs, respondents were asked whether they had heard of FP methods such as male condom, injectables and female sterilization among others. Those who had heard about a method were further asked if they 
had ever used, or were still using any. Also, female respondents were asked about the places where they accessed their current FP methods at the time they started using it. Women currently using a FP method were asked if they used it during the last sexual intercourse and if so, which specific method it was. Questionnaires were administered by trained staff in the respondents' homes.

\subsection{Sampling}

The respondents sampled for this survey came from all 156 communities of the KHDSS. Sample size estimates were computed for women of reproductive age. A total of 5485 women of reproductive age were randomly sampled out of a total resident population of 35,735 women in reproductive age. This sample was based on an estimated proportion of $29.0 \%$ females of reproductive age recently documented to be using any contraceptive method from Brong-Ahafo Region [4]. The male partners of 1845 female respondents were also interviewed. To attain a representative sample of young males, an additional 509 males aged between 15 and 24 years were randomly sampled out of their resident population of 14,450 based on the assumption that $29.8 \%$ of males aged 15 to 24 would have had sex with either a non-married or non-cohabiting partner within the past 12 months [4].

\subsection{Quantitative Data Management and Analysis}

Data were double-entered into Microsoft FoxPro 9.0, cleaned and verified. Socio-demographic characteristics of the respondents such as age, education, religion, district of residence and type of place of residence were extracted from KHDSS data collected in 2010/2011. The data were then analyzed using STATA11.1. Socio-demographic characteristics of the respondents were described using proportions.

\subsection{Qualitative Data and Analysis}

Thematic areas generated from initial survey findings were further explored using six Focused Group Discussions (FGDs) among men and women aged 15 - 49 years who were not part of the earlier survey but were residents in the study area. Discussion groups comprised of 8 - 12 persons; men and women were separately placed in three age-groups (15 - 25, 26 - 36, 37 - 49 years). The discussions were conducted in the local language (Twi), tape-recorded, translated and transcribed into English. Thematic analysis of data was performed using QSR Nvivo software (Version 8). The results of the FGDs were triangulated and reported with illustrative quotes.

\subsection{Ethical Review}

The Kintampo Health Research Centre Institutional Ethics Committee (KHRC IEC) approved the study before implementation. Written consent was obtained from all adult respondents (i.e. those aged 18 years or more) and from parents of respondents less than 18 years of age and also assent from the young respondents themselves. Confidentiality of data collected was maintained by storing them at the secured data bank in KHRC.

\section{Results}

Out of a potential 7839 respondents contacted, 7171 made up of 4956 females and 2225 males, completed the survey interviews successfully.

\subsection{Demographic Characteristics of the Study Population}

A fifth (20.4\%) and three-fifths (60.0\%) of females ranged between ages 15 - 19 years and 20 - 39 years respectively (Table 1). Close to thirty-eight percent (37.9\%) of all respondents had no formal education, $21.6 \%$ had primary education, $26.4 \%$ had Middle/Junior High School education and $10.2 \%$ had secondary or higher education. Much more females than males (22.7\% against $19.1 \%)$ had primary and (27.2\% against $24.4 \%)$ had middle/junior high school education. A little over one fifth (21.8\%) of all respondents were unmarried. The proportion of females and males married or living together was $67.7 \%$ and $80.5 \%$ respectively. Just over half (55.3\%) of the respondents were Christians compared with 28.3\% Moslems; the remaining $16.4 \%$ belonging to other faiths. Majority of respondents (65.1\%) were from rural communities in the surveyed area (Table 1).

\subsection{Awareness of FP Methods}

Awareness of any FP method and modern methods were very high (97\%) among all respondents and there was 
little gender variation; that of traditional methods was however relatively lower (74.3\%) (Table 2). Awareness of male condom was the highest (92.4\%), followed by injectables (88.3\%), female sterilization (83.2\%), the pill (81.6\%); with the diaphragm being the least known $(19.1 \%)$. Of the traditional FP methods, awareness was

\section{Table 1. Demographic characteristics of survey sample.}

\begin{tabular}{|c|c|c|c|c|c|c|}
\hline \multirow{3}{*}{$\begin{array}{c}\text { Characteristics } \\
\text { Age }\end{array}$} & \multicolumn{6}{|c|}{ Gender } \\
\hline & \multicolumn{2}{|c|}{ Female $(\mathrm{N}=4956)$} & \multicolumn{2}{|c|}{ Male (N = 2225) } & \multicolumn{2}{|c|}{ Total $(\mathrm{N}=\mathbf{7 1 7 1})$} \\
\hline & $\mathrm{n}$ & $\%$ & $\mathrm{n}$ & $\%$ & $\mathrm{n}$ & $\%$ \\
\hline $15-19$ & 1008 & 20.4 & 293 & 13.2 & 1301 & 18.1 \\
\hline $20-24$ & 835 & 16.9 & 246 & 11.1 & 1081 & 15.1 \\
\hline $25-29$ & 777 & 15.7 & 160 & 7.2 & 937 & 13.1 \\
\hline $30-34$ & 739 & 14.9 & 249 & 11.2 & 988 & 13.8 \\
\hline $35-39$ & 618 & 12.5 & 263 & 11.8 & 881 & 12.3 \\
\hline $40-44$ & 538 & 10.9 & 291 & 13.1 & 829 & 11.6 \\
\hline $45-49$ & 431 & 8.7 & 237 & 10.7 & 668 & 9.3 \\
\hline $50-54$ & 0 & 0 & 189 & 8.5 & 189 & 2.6 \\
\hline $55-59$ & 0 & 0 & 128 & 5.8 & 128 & 1.8 \\
\hline $60+$ & 0 & 0 & 169 & 7.6 & 169 & 2.4 \\
\hline \multicolumn{7}{|l|}{ Education } \\
\hline No Education & 1813 & 36.6 & 906 & 40.7 & 2719 & 37.9 \\
\hline Primary & 1127 & 22.7 & 425 & 19.1 & 1552 & 21.6 \\
\hline Middle/Junior High School & 1348 & 27.2 & 544 & 24.4 & 1892 & 26.4 \\
\hline Secondary + & 464 & 9.4 & 270 & 12.1 & 734 & 10.2 \\
\hline Missing $^{\mathrm{a}}$ & 204 & 4.1 & 80 & 3.6 & 284 & 4.0 \\
\hline \multicolumn{7}{|l|}{ Marital Status } \\
\hline Never Married & 1155 & 23.4 & 411 & 18.5 & 1566 & 21.8 \\
\hline Married/Living Together & 3301 & 66.7 & 1792 & 80.5 & 5093 & 71.0 \\
\hline Widowed/Divorced/Separated & 417 & 8.4 & 7 & 0.3 & 424 & 5.9 \\
\hline Missing $^{\mathrm{a}}$ & 73 & 1.5 & 15 & 0.7 & 88 & 1.2 \\
\hline \multicolumn{7}{|l|}{ Religion } \\
\hline Catholic & 919 & 18.5 & 356 & 16.0 & 1275 & 17.8 \\
\hline Protestant & 496 & 10.0 & 182 & 8.2 & 678 & 9.5 \\
\hline Pentecostal/Charismatic & 1102 & 22.2 & 377 & 16.9 & 1479 & 20.6 \\
\hline Other Christian & 393 & 7.9 & 140 & 6.3 & 533 & 7.4 \\
\hline Moslem & 1326 & 26.8 & 700 & 31.5 & 2026 & 28.3 \\
\hline Traditional/Spiritualist & 161 & 3.2 & 112 & 5.0 & 273 & 3.8 \\
\hline No Religion & 304 & 6.1 & 251 & 11.3 & 555 & 7.7 \\
\hline Other Religions & 57 & 1.2 & 29 & 1.3 & 86 & 1.2 \\
\hline Missing $^{\mathrm{a}}$ & 198 & 4.0 & 78 & 3.5 & 276 & 3.8 \\
\hline \multicolumn{7}{|l|}{ District } \\
\hline North & 3014 & 60.9 & 1255 & 56.4 & 4269 & 59.5 \\
\hline South & 1932 & 39.1 & 970 & 43.6 & 2902 & 40.5 \\
\hline \multicolumn{7}{|l|}{ Place of Residence } \\
\hline Rural & 3040 & 61.5 & 1631 & 73.3 & 4671 & 65.1 \\
\hline Urban & 1906 & 38.5 & 594 & 26.7 & 2500 & 34.9 \\
\hline
\end{tabular}

${ }^{a}$ Was missing from the KHDSS data because respondent was not present during the KHDSS survey when socio-demographic characteristics were collected. 
Table 2. Respondents awareness of FP methods.

\begin{tabular}{|c|c|c|c|c|c|c|}
\hline \multirow{3}{*}{$\begin{array}{c}\text { Characteristics } \\
\text { Method }\end{array}$} & \multicolumn{6}{|c|}{ Gender } \\
\hline & \multicolumn{2}{|c|}{ Female $(N=4946)$} & \multicolumn{2}{|c|}{ Male (N = 2225) } & \multicolumn{2}{|c|}{ Total $(N=7171)$} \\
\hline & $\mathbf{n}$ & $\%$ & $\mathbf{n}$ & $\%$ & $\mathbf{n}$ & $\%$ \\
\hline Any Method & 4772 & 96.5 & 2174 & 97.7 & 6946 & 96.9 \\
\hline Any Modern Method & 4766 & 96.4 & 2173 & 97.7 & 6939 & 96.8 \\
\hline Any Traditional Method & 3574 & 72.3 & 1757 & 79.0 & 5331 & 74.3 \\
\hline \multicolumn{7}{|l|}{ Modern Methods } \\
\hline Male Condom & 4494 & 90.9 & 2129 & 95.7 & 6623 & 92.4 \\
\hline Injectables & 4392 & 88.8 & 1943 & 87.3 & 6335 & 88.3 \\
\hline Female Sterilization & 4079 & 82.5 & 1885 & 84.7 & 5964 & 83.2 \\
\hline Pills & 4032 & 81.5 & 1819 & 81.8 & 5851 & 81.6 \\
\hline Female Condom & 3689 & 74.6 & 1854 & 83.3 & 5543 & 77.3 \\
\hline Implant & 3446 & 69.7 & 1313 & 59.0 & 4759 & 66.4 \\
\hline IUD & 2276 & 46.0 & 1019 & 45.8 & 3295 & 45.9 \\
\hline Emergency & 1546 & 31.3 & 651 & 29.3 & 2197 & 30.6 \\
\hline Male Sterilization & 1183 & 23.9 & 856 & 38.5 & 2039 & 28.4 \\
\hline Foam & 1124 & 22.7 & 650 & 29.2 & 1774 & 24.7 \\
\hline Diaphragm & 876 & 17.7 & 497 & 22.3 & 1373 & 19.1 \\
\hline \multicolumn{7}{|l|}{ Natural/Traditional Methods } \\
\hline Rhythm & 3282 & 66.4 & 1539 & 69.2 & 4821 & 67.2 \\
\hline Withdrawal & 2336 & 47.2 & 1336 & 60.0 & 3672 & 51.2 \\
\hline LAM & 2150 & 43.5 & 923 & 41.5 & 3073 & 42.9 \\
\hline Other Methods & 60 & 1.2 & 37 & 1.7 & 97 & 1.4 \\
\hline
\end{tabular}

highest for rhythm (67.2\%) and least for lactational amenorrhoea method (LAM) (42.9\%). Over a quarter (28.4\%) of respondents had heard of male sterilization, with awareness among females being $15 \%$ lower than that among males. Close to a third (30.6\%) of the population were aware of emergency contraception. At least three-quarters of respondents (77.3\%) were aware of female condom with males exhibiting a higher level of awareness (83.3\%) than females (74.6\%) (Table 2). On average, respondents were aware of 8 methods (females 7.9, males 8.3).

\subsection{Sources of FP Messages}

The most common source of FP messages was the radio (50.4\%), followed by social events/games (29.2\%) and television (28.2\%) (Table 3). Magazines were the least (8.9\%) reported source of FP messages. There were differences in the sources of FP messages among males and females with a higher proportion of males (62.8\%) receiving FP from radio than females (44.8\%) (Table 3).

\subsection{Ever Use of a FP Method}

About half of the respondents (i.e. female 55\% and males 51\%) reported they had ever used a FP method (Table 4). Use of a modern method was two times higher (46.1\%) than that of a traditional methods (22.7\%). Injectables were the predominant FP method used among females followed by the pills; the two methods accounted for close to half (46\%) of the methods used by female respondents. Less than $5 \%$ of females patronized emergency contraceptives. Only $1.7 \%$ females reported they have been sterilized in the past; no male sterilization 
Table 3. Sources of FP messages.

\begin{tabular}{|c|c|c|c|c|c|c|}
\hline \multirow{3}{*}{$\begin{array}{c}\text { Characteristics } \\
\text { Source }\end{array}$} & \multicolumn{6}{|c|}{ Gender } \\
\hline & \multicolumn{2}{|c|}{ Female $(N=4946)$} & \multicolumn{2}{|c|}{ Male (N = 2225) } & \multicolumn{2}{|c|}{ Total $(\mathrm{N}=7171)$} \\
\hline & $\mathbf{n}$ & $\%$ & $\mathbf{n}$ & $\%$ & $\mathbf{n}$ & $\%$ \\
\hline Radio & 2215 & 44.8 & 1398 & 62.8 & 3613 & 50.4 \\
\hline Social Events/Games & 1526 & 30.9 & 566 & 25.4 & 2092 & 29.2 \\
\hline Television & 1370 & 27.7 & 655 & 29.4 & 2025 & 28.2 \\
\hline Shop/Spot & 916 & 18.5 & 375 & 16.9 & 1291 & 18.0 \\
\hline Poster & 904 & 18.3 & 542 & 24.4 & 1446 & 20.2 \\
\hline Magazine & 320 & 6.5 & 320 & 14.4 & 640 & 8.9 \\
\hline
\end{tabular}

Table 4. Respondents who have ever used a FP method.

\begin{tabular}{|c|c|c|c|c|}
\hline \multirow{3}{*}{$\begin{array}{c}\text { Characteristics } \\
\text { Method }\end{array}$} & \multicolumn{4}{|c|}{ Gender } \\
\hline & \multicolumn{2}{|c|}{ Female $(N=4946)$} & \multicolumn{2}{|c|}{ Male (N = 2225) } \\
\hline & $\mathbf{n}$ & $\%$ & $\mathbf{n}$ & $\%$ \\
\hline Any Method & 2712 & 54.8 & 1144 & 51.4 \\
\hline Any Modern Method & 2408 & 48.7 & 1026 & 46.1 \\
\hline Any Traditional Method & 1166 & 23.6 & 506 & 22.7 \\
\hline \multicolumn{5}{|l|}{ Modern Methods } \\
\hline Injectables & 1155 & 23.4 & 379 & $17.0^{\mathrm{a}}$ \\
\hline Pills & 1120 & 22.6 & 380 & $17.1^{\mathrm{a}}$ \\
\hline Male Condom & 604 & $12.2 \mathrm{a}$ & 526 & 23.6 \\
\hline Emergency Contraception & 204 & 4.1 & 42 & $1.9^{\mathrm{a}}$ \\
\hline Implant & 103 & 2.1 & 44 & $2.0^{\mathrm{a}}$ \\
\hline Female Sterilization & 84 & 1.7 & 59 & $2.7^{\mathrm{a}}$ \\
\hline IUD & 77 & 1.6 & 20 & $0.9^{\mathrm{a}}$ \\
\hline Female Condom & 36 & 0.7 & 25 & $1.1^{\mathrm{a}}$ \\
\hline Foam & 35 & 0.7 & 28 & $1.3^{\mathrm{a}}$ \\
\hline Diaphragm & 7 & 0.1 & 5 & $0.2^{\mathrm{a}}$ \\
\hline Male Sterilization & 0 & 0.0 & 0 & 0.0 \\
\hline \multicolumn{5}{|l|}{ Natural/Traditional Methods } \\
\hline Rhythm & 900 & 18.2 & 358 & 16.1 \\
\hline Withdrawal & 472 & 9.5 & 226 & 10.2 \\
\hline LAM & 455 & 9.2 & 164 & $7.4^{\mathrm{a}}$ \\
\hline Other Methods & 27 & 0.6 & 12 & 0.5 \\
\hline
\end{tabular}

${ }^{\mathrm{a}}$ Respondents whose partners had ever used a given method.

was reported in this population. From respondents, the rhythm method was the most used traditional FP method (18.2\% females and $16.1 \%$ males), followed by the withdrawal (9.5\% female and $10.2 \%$ male), with LAM being the least used (9.2\% female and 7.4\% male) (Table 4). An average of one FP method was used by respondents in this population. 


\subsection{Knowledge of Sources Where FP Methods Could Be Obtained}

Three-fourths (73.9\%) of respondents knew a place where they could obtain FP services and this did not vary much by gender (Table 5). Seven out of ten males (71.5\%) knew where to obtain condoms, with a majority of them preferring the private sector $(54.2 \%)$ over the public (44.9\%). Over $85 \%$ of respondents ( $87 \%$ female and $88 \%$ male) knew of the public health sector, followed by the private sector $(11.7 \%)$ and others sources $(1.2 \%)$, as venues to obtain FP methods and services. The public health sector dominated the sources of FP methods; injectables, intrauterine device (IUD) implants and sterilization for example are usually administered at health facilities. A female participant's concern raised in an FGD goes to confirm this assertion: "Something like the injection (injectables); you need (a) qualified health personnel to attend to you".

\subsection{Current Contraceptive Use among Married and Sexually Active Unmarried Women}

The contraceptive prevalence rate (CPR) for any method among married and unmarried sexually active women was $25.3 \%$ and $43.5 \%$ respectively. The injectables (32.4\%) was the most frequently used contraceptive among married women, followed by the pill (26.2\%); the reverse was however observed among unmarried sexually active women (i.e. 34.7\% pills and 20.2\% injectables) (Table 6). Current use of male condoms was higher (11.5\%) among sexually active unmarried women compared to $1.5 \%$ in married women. Constituting less than one percent of current contraceptive use, the foam/jelly, diaphragm, IUDs, female condoms and emergency contraception could be considered unpopular among the population surveyed. The rhythm method was more popular among sexually active unmarried women (23.8\%) as compared to the married (16.3\%) (Table 6).

\subsection{Perceptions about FP and Contraception}

Majority of respondents considered FP as a way of reducing the number of unwanted pregnancies and abortions (81.8\%) and maternal deaths from complications of pregnancy and childbirth (72\%) (Table 7). FP was also seen as improving overall health and wellbeing (79.5\%) as well as health of mothers and children (79.2\%). About half of all respondents (46.9\% female and $55.6 \%$ males) perceived contraceptive use as ways of encouraging promiscuity among women. More females (46.3\%) than males (37.5\%) viewed contraception as the responsibility of women (Table 7). The FGDs endorsed such findings: “...I think it is the woman and the daughter who really need family planning...” (male respondent)... and “...What I know is that family planning is good for women and their daughters because they are closer to each other than the father so it is of more benefit to women and their daughters....” (male respondent)

Most (85.5\%) respondents agreed that children born into smaller families were more likely to succeed in life (Table 7). This was demonstrated by the view of a female respondent: “...When I gave birth without spacing them, I really suffered but since I started using it (family planning) I have been able to space my children...I have (also) been able to save some money that I am hoping to use to support my child to continue her education."

Majority of males (78.9\%) were aware that breastfeeding women could become pregnant; 73\% knew of days within the menstrual cycle when women were more likely to become pregnant.

Table 5. Knowledge of a place where FP services could be or were obtained.

\begin{tabular}{|c|c|c|c|c|c|c|}
\hline \multirow{3}{*}{$\begin{array}{c}\text { Characteristics } \\
\text { Source }\end{array}$} & \multicolumn{6}{|c|}{ Gender } \\
\hline & \multicolumn{2}{|c|}{ Female $(N=3644)$} & \multicolumn{2}{|c|}{ Male $(\mathrm{N}=1660)$} & \multicolumn{2}{|c|}{ Total $(N=5304)$} \\
\hline & $\mathbf{n}$ & $\%$ & $\mathbf{n}$ & $\%$ & $\mathbf{n}$ & $\%$ \\
\hline Public Medical & 3163 & 86.8 & 1459 & 87.8 & 4622 & 87.2 \\
\hline Private Medical & 424 & 11.7 & 194 & 11.7 & 618 & 11.7 \\
\hline Other & 57 & 1.5 & 7 & 0.5 & 64 & 1.2 \\
\hline
\end{tabular}

NB: Public medical sources include government hospitals/polyclinics, health centers, health posts, CHPS, FP clinics, mobile clinics/outreach services, community based surveillance volunteers (CBSV), field workers and peer educators. Private medical sources include private hospitals/clinics/pharmacies, chemical shops, Planned Parenthood Association of Ghana (PPAG) and maternity homes. Other sources include shops, religious institutions, friends/relatives, drug peddlers and herbalists. 
Table 6. Current contraceptive use among currently married and sexually active unmarried women.

\begin{tabular}{|c|c|c|c|c|c|c|}
\hline \multirow{3}{*}{$\begin{array}{c}\text { Characteristics } \\
\text { Method }\end{array}$} & \multicolumn{6}{|c|}{ Gender } \\
\hline & \multicolumn{2}{|c|}{ Married $(\mathrm{N}=2327)$} & \multicolumn{2}{|c|}{ Sexually Active Unmarried $(\mathrm{N}=\mathbf{8 2 1})$} & \multicolumn{2}{|c|}{ Total $(\mathrm{N}=3148)$} \\
\hline & $\mathbf{n}$ & $\%$ & $\mathbf{n}$ & $\%$ & $\mathbf{n}$ & $\%$ \\
\hline Any Method & 589 & 25.3 & 357 & 43.5 & 946 & 30.1 \\
\hline Any Modern Method & 445 & 19.1 & 247 & 30.1 & 692 & 22.0 \\
\hline Any Traditional Method & 144 & 6.2 & 110 & 13.4 & 254 & 8.1 \\
\hline \multicolumn{7}{|l|}{ Modern Methods } \\
\hline Injectables & 191 & 32.4 & 72 & 20.2 & 278 & 27.8 \\
\hline Pills & 154 & 26.2 & 124 & 34.7 & 263 & 29.4 \\
\hline Female Sterilization & 73 & 12.4 & 6 & 1.7 & 79 & 8.4 \\
\hline Implant & 12 & 2.0 & 3 & 0.8 & 15 & 1.6 \\
\hline Male Condom & 9 & $1.5 \mathrm{a}$ & 41 & $11.5^{\mathrm{a}}$ & 50 & 5.3 \\
\hline Foam & 2 & 0.3 & 0 & 0.0 & 2 & 0.2 \\
\hline Jelly/diaphragm & 2 & 0.3 & 0 & 0.0 & 2 & 0.2 \\
\hline IUD & 1 & 0.2 & 0 & 0.0 & 1 & 0.1 \\
\hline Female Condom & 1 & 0.2 & 1 & 0.9 & 2 & 0.2 \\
\hline Emergency Contraception & 0 & 0.0 & 0 & 0.0 & 0 & 0.0 \\
\hline Male Sterilization & 0 & 0.0 & 0 & 0.0 & 0 & 0.0 \\
\hline \multicolumn{7}{|l|}{ Natural/Traditional Methods } \\
\hline Rhythm & 96 & 16.3 & 85 & 23.8 & 181 & 19.1 \\
\hline LAM & 18 & 3.1 & 0 & 0.0 & 18 & 1.9 \\
\hline Withdrawal & 13 & 2.2 & 7 & 2.0 & 20 & 2.1 \\
\hline Other Methods & 17 & 2.9 & 18 & 5.0 & 35 & 3.7 \\
\hline
\end{tabular}

${ }^{\mathrm{a}}$ Respondents whose partners had ever used a given method; ${ }^{\mathrm{b}}$ Sexually active refers to sexual intercourse within the last 30 days.

Table 7. Perceptions about FP and contraception.

\begin{tabular}{|c|c|c|c|c|c|c|}
\hline \multirow{3}{*}{$\begin{array}{c}\text { Characteristics } \\
\text { Statement about FP }\end{array}$} & \multicolumn{6}{|c|}{ Gender } \\
\hline & \multicolumn{2}{|c|}{$\begin{array}{c}\text { Female } \\
(\mathrm{N}=4946)\end{array}$} & \multicolumn{2}{|c|}{$\begin{array}{c}\text { Male } \\
(\mathrm{N}=2225)\end{array}$} & \multicolumn{2}{|c|}{$\begin{array}{c}\text { Total } \\
(\mathrm{N}=7171)\end{array}$} \\
\hline & $\mathrm{n}$ & $\%$ & $\mathrm{n}$ & $\%$ & $\mathrm{n}$ & $\%$ \\
\hline Reduces number of unwanted pregnancies and abortions & 3973 & 80.3 & 1891 & 85.0 & 5864 & 81.8 \\
\hline Improves overall health and wellbeing & 3819 & 77.2 & 1882 & 84.6 & 5701 & 79.5 \\
\hline Improves the health of mothers and children & 3811 & 77.1 & 1866 & 83.9 & 5677 & 79.2 \\
\hline Reduces the death of mothers from complications of pregnancy and childbirth & 3399 & 68.7 & 1767 & 79.4 & 5166 & 72.0 \\
\hline \multicolumn{7}{|l|}{ Statement about contraception } \\
\hline It is better not to have more children than you can take care of & 4538 & 91.8 & 2000 & 89.9 & 6538 & 91.2 \\
\hline Children in small families are more likely to succeed in life & 4263 & 86.2 & 1865 & 83.8 & 6128 & 85.5 \\
\hline Having too many children may be dangerous for a woman & 4091 & 82.7 & 1827 & 82.1 & 5918 & 82.5 \\
\hline Women who use contraception may become promiscuous & 2322 & 46.9 & 1236 & 55.6 & 3558 & 49.6 \\
\hline Contraception is women's responsibility and a man should not have to worry about it & 2290 & 46.3 & 835 & 37.5 & 3125 & 43.6 \\
\hline
\end{tabular}




\section{Discussion}

This study sought to describe characteristics influencing FP use in the Kintampo districts of Ghana. These were knowledge and use of FP, access to FP and perceptions about FP. The data comes from a representative sample of the population under study and would serve as a baseline for future updates. The KHDSS platform makes it feasible to follow the same cohort of study participants in future updates. Mixed-methods employed in the survey places in context the findings and make them relevant to the needs of the study population.

\subsection{Awareness and Use of FP Methods}

In the surveyed population, awareness was higher compared to use of FP methods, similar to findings from other studies [5]-[7]. Awareness of modern methods was also significantly higher than that of traditional methods. The gap between knowledge and use may reflect the influence of a number of socio-cultural and economic factors that hinder access to and acceptance of FP methods. Some of these factors are poor female decision-making power [10], poor economic resources [11], low quality of care at FP services [12] and desire for large families [13]. For many sub-Saharan African countries, it is imperative to make contraceptive services more socially and economically accessible to women and their spouses; and this need is particularly pressing for couples in rural areas, where access to services is far below what is desired.

Contraceptive use among married women in the surveyed population was marginally higher than the Ghana national average of $23.5 \%$ [4]. Pills and injectables were the most currently used methods among married and sexually active unmarried women respectively, as per their own reports and those of their partners within the Kintampo districts. Respondents from a study in urban Ghana showed higher levels of use of pills among married women in contrast to the current study, where injectables were the most prevalent [14]. The reason for this situation may be largely due to their availability and publicity compared to other methods such as foam/jelly, diaphragm, IUDs, female condoms and emergency contraception, which are not usually advertised [12]-[14]. For males however, the male condom was the most ever used method. The male condom was less popular in the female study population, however the sexually active unmarried females' current use was more than that of the married. Reasons such as lack of trust, wanting to become pregnant, stigma of associating condoms with HIV and STIs from prior prevention campaigns among others have been associated with community members avoiding condom use [15] [16].

It was observed that unmarried sexually active females used any, modern and traditional methods of contraception much more than married females in this surveyed population. The rhythm method was the most prominent of traditional methods used and non-married females "out-used” their married counterparts. The rhythm/ calendar method has been shown to be quite effective and satisfactory among relatively rural populations [17].

\subsection{Sources of FP Information}

Just like previous studies, radio (mass media) was identified as the most popular FP dissemination means [18], [19]. The current study identified other relevant and growing sources of FP message dissemination; this has been found to be social activities such as going to the market, fetching water, games, and visits to hairdresser's saloons. This can serve as a cheap means for FP messaging.

\subsection{Awareness of Sources of Contraceptives}

Contraceptives in the surveyed population were accessed from diverse sources as documented in earlier studies. Among them are public medical facilities under the health ministry, non-governmental health institutions (private health facilities, pharmacy/chemical sellers) and other sources such as friends and religious bodies [4]. It was evident however that, FP services still reside within health institutions, possibly because the methods available require expertise from within such facilities significantly determining the source of service [20] [21]. The private sector, mostly chemical shops serve as sources of non-clinical contraceptives such as condoms and pills [20] [21], as shown in the current survey results.

\subsection{Perceptions about FP and Contraception}

Perceptions about FP and contraception were generally positive and very encouraging. Male attitudes, or percep- 
tions of male attitudes towards FP are often a significant barrier for women [18] [19]. The perception by more males than females that FP leads to female promiscuity is worrying and requires attention and efforts to change. Another unfavorable perception is the view that contraception is women's responsibility and that men should not have to worry about it. This perception does not encourage high contraceptive uptake [22] [23]. Joint decision-making by couples about the use of FP is a key determinant of contraceptive use [22] [23]. Findings from other studies suggest that factual information on FP encourages contraceptive use, while myths and misinformation discourages its use [24]-[27].

\subsection{Limitations}

These analyses were based on self-reported sexual behaviour, which could be affected by some biases of underreporting or over reporting [28]. To minimise responder biases from answering personal questions such as FP use, interviewers were trained specifically with the skill of establishing rapport and questioning.

\subsection{Conclusions and Recommendations}

Findings from this study have depicted some essential shortfalls in the FP needs of the surveyed population that require action. It has also demonstrated some similarities and divergence from the FP picture within the country Ghana. Recommendations provided are mainly to policy makers, program implementers and healthcare providers.

Awareness of emergency contraception is low, so is its use. This calls for a proactive informational campaign by program implementers and healthcare providers to enhance knowledge and use by the populace. The prominence of the rhythm method among the traditional methods, more-so among the non-married makes it a potential for promotion among the population. Providing appropriate education to the population on its accurate utilization will enhance its effectiveness.

Radio was found to be an essential source of FP messages, as such program implementers should continue its use for dissemination of messages. Social activities have also shown a potential of enhancing message dissemination and should be considered as additional or alternate to radio to enhance information spread.

As majority of the study population would go to health facilities to access FP methods, policy makers should ensure that health facilities have adequate staff strength and expertise to provide such services. Health care providers should also make themselves accessible and provide satisfactory care to their clients. Methods however, that do not require specific clinical expertise should continue being made available in non-health institutions to increase access.

To address the perceptions of promiscuity associated with female FP use and FP use being the responsibility of women alone, program implementers and healthcare providers should devise and implement evidence-based educational messages and supplement them with role models to disabuse the minds of community members. Contraceptives in the surveyed population were accessed from diverse sources as documented in earlier studies.

\section{Acknowledgements}

The authors wish to thank the Municipal and District Assemblies, chiefs, elders, opinion leaders and community members in the Kintampo North Municipality and Kintampo South District for their goodwill and participation in the health and demographic surveillance system. We also wish to thank Mrs. Alice Vorleto and the entire Kintampo North Municipal Health Management Team for their assistance in training field staff on sensitive aspects of the survey tool, all field and computer centre staff. This study was conducted with funds from the KHRC research fund.

\section{References}

[1] United Nations (2011) World Population Prospects, the 2010 Revision. http://scholar.google.com/scholar?q=World+Population+Prospects:+The+2010+Revision\&btnG=\&hl=en\&as sdt=0,5\#5

[2] Cleland, J., Bernstein, S., Ezeh, A., Faundes, A., Glasier, A. and Innis, J. (2006) Family Planning: The Unfinished Agenda. The Lancet, 368, 1810-1827. http://dx.doi.org/10.1016/S0140-6736(06)69480-4

[3] National Population Council (1994) National Population Policy of Ghana. Government of Ghana, Accra.

[4] Ghana Statistical Service, Ghana Health Service, and ICS Macro (2009) Ghana Demographic and Health Survey 2008. Accra. 
[5] Aryeetey, R., Kotoh, A.M. and Hindin, M.J. (2010) Knowledge, Perceptions and Ever Use of Modern Contraception among Women in the Ga East District, Ghana. African Journal of Reproductive Health, 14, 27-32.

[6] Bawah, A.A., Akweongo, P., Simmons, R. and Phillips, J.F. (1999) Women's Fears and Men’s Anxieties: The Impact of Family Planning on Gender Relations in Northern Ghana. Studies in Family Planning, 30, 54-66. http://dx.doi.org/10.1111/j.1728-4465.1999.00054.x

[7] Adanu, R.M.K., Seffah, J.D., Hill, A.G., Darko, R. and Rosemary, B. (2009) Contraceptive Use by Women in Accra, Ghana : Results from the 2003 Accra Women's Health Survey. African Journal of Reproductive Health, 13, 123-134.

[8] Parr, N.J. (2003) Discontinuation of Contraceptive Use in Ghana. Journal of Health, Population and Nutrition, 21, 150-157.

[9] Owusu-Agyei, S., Nettey, O.E.A., Zandoh, C., Sulemana, A., Adda, R., Amenga-Etego, S. and Mbacke, C. (2012) Demographic Patterns and Trends in Central Ghana: Baseline Indicators from the Kintampo Health and Demographic Surveillance System. Global Health Action, 5, 1-11.

[10] Chapagain, M. (2005) Masculine Interest behind High Prevalence of Female Contraceptive Methods in Rural Nepal. Australian Journal of Rural Health, 13, 35-42 http://dx.doi.org/10.1111/j.1440-1854.2004.00643.x

[11] Stephenson, R. and Tsui, A.O. (2002) Contextual Influences on Reproductive Health Service Use in Uttar Pradesh, India. Studies in Family Planning, 33, 309-320. http://dx.doi.org/10.1111/j.1728-4465.2002.00309.x

[12] Hamid, S. and Stephenson, R. (2006) Provider and Health Facility Influences on Contraceptive Adoption in Urban Pakistan. International Family Planning Perspectives, 32, 71-78. http://dx.doi.org/10.1363/3207106

[13] Bankole, A. and Singh, S. (1998) Couples' Fertility and Contraceptive Decision-Making in Developing Countries: Hearing the Man’s Voice. International Family Planning Perspectives, 24, 15-24. http://dx.doi.org/10.2307/2991915

[14] Cox, C.M., Hindin, M.J., Otupiri, E. and Larsen-Reindorf, R. (2013) Understanding Couples’ Relationship Quality and Contraceptive Use in Kumasi, Ghana. International Perspectives on Sexual and Reproductive Health, 39, 185-194. http://dx.doi.org/10.1363/3918513

[15] Chacko, S., Kipp, W., Laing, L. and Kabagambe, G. (2007) Knowledge of and Perceptions about Sexually Transmitted Diseases and Pregnancy: A Qualitative Study among Adolescent Students in Uganda. Journal of Health, Population and Nutrition, 25, 319-327.

[16] Baumgartner, J.N., Lugina, H., Johnson, L. and Nyamhanga, T. (2010) "Being Faithful” in a Sexual Relationship: Perceptions of Tanzanian Adolescents in the Context of HIV and Pregnancy Prevention. AIDS Care, 22, 1153-1158. http://dx.doi.org/10.1080/09540121003615095

[17] Burkhart, M., de Mazariegos, L., Salazar, S. and Lamprecht, V.M. (2000) Effectiveness of a Standard-Rule Method of Calendar Rhythm among Mayan Couples in Guatemala. International Family Planning Perspectives, 26, 131-136. http://dx.doi.org/10.2307/2648302

[18] Olenick, I. (2000) Women's Exposure to Mass Media Is Linked to Attitudes toward Contraception in Pakistan, India and Bangladesh. International Family Planning Perspectives, 26, 48-50. http://dx.doi.org/10.2307/2648294

[19] Olaleye, D.O. and Bankole, A. (1994) The Impact of Mass Media Family Planning Promotion on Contraceptive Behavior of Women in Ghana. Population Research and Policy Review, 13, 161-177. http://dx.doi.org/10.1007/BF01080201

[20] Agha, S. and Do, M. (2008) Does an Expansion in Private Sector Contraceptive Supply Increase Inequality in Modern Contraceptive Use? Health Policy and Planning, 23, 465-475. http://dx.doi.org/10.1093/heapol/czn035

[21] Hotchkiss, D.R., Godha, D. and Do, M. (2011) Effect of an Expansion in Private Sector Provision of Contraceptive Supplies on Horizontal Inequity in Modern Contraceptive Use: Evidence from Africa and Asia. International Journal for Equity in Health, 10, 33. http://dx.doi.org/10.1186/1475-9276-10-33

[22] Feyisetan, B.J. (2000) Spousal Communication and Contraceptive Use among the Yoruba of Nigeria. Population Research and Policy Review, 19, 29-45. http://dx.doi.org/10.1023/A:1006388011947

[23] Ogunjuyigbe, P.O., Ojofeitimi, E.O. and Liasu, A. (2009) Spousal Communication, Changes in Partner Attitude, and Contraceptive Use among the Yorubas of Southwest Nigeria. Indian Journal of Community Medicine: Official Publication of Indian Association of Preventive \& Social Medicine, 34, 112. http://dx.doi.org/10.4103/0970-0218.51232

[24] Ankomah, A., Anyanti, J. and Oladosu, M. (2011) Myths, Misinformation, and Communication about Family Planning and Contraceptive Use in Nigeria. Open Access Journal of Contraception, 2, 95-105. http://dx.doi.org/10.2147/OAJC.S20921

[25] Otoide, V., Oronsaye, F. and Okonofua, F.E. (2001) Why Nigerian Adolescents Seek Abortion Rather than Contraception: Evidence from Focus-Group Discussions. International Family Planning Perspectives, 27, 77-81. http://dx.doi.org/10.2307/2673818

[26] Rutenberg, N. and Watkins, S. (1997) The Buzz outside the Clinics: Conversations and Contraception in Nyanza Pro- 
vince, Kenya. Studies in Family Planning, 28, 290-307. http://dx.doi.org/10.2307/2137860

[27] DeClerque, J., Tsui, A.O., Abul-Ata, M.F., Abul-Ata, M.F. and Barcelona, D. (1986) Rumor, Misinformation and Oral Contraceptive Use in Egypt. Social Science \& Medicine, 23, 83-92. http://dx.doi.org/10.1016/0277-9536(86)90327-8

[28] Meekers, D. and Van Rossem, R. (2005) Explaining Inconsistencies between Data on Condom Use and Condom Sales. BMC Health Services Research, 5, 5. http://dx.doi.org/10.1186/1472-6963-5-5 
Scientific Research Publishing (SCIRP) is one of the largest Open Access journal publishers. It is currently publishing more than 200 open access, online, peer-reviewed journals covering a wide range of academic disciplines. SCIRP serves the worldwide academic communities and contributes to the progress and application of science with its publication.

Other selected journals from SCIRP are listed as below. Submit your manuscript to us via either submit@scirp.org or Online Submission Portal.
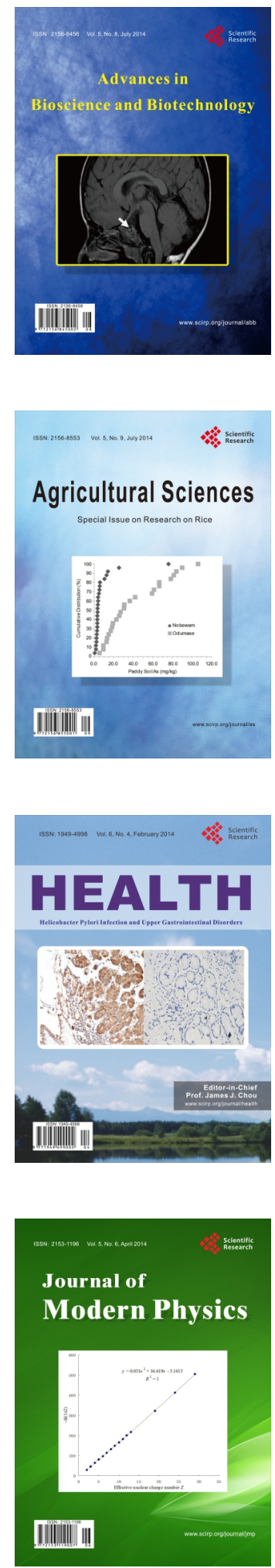
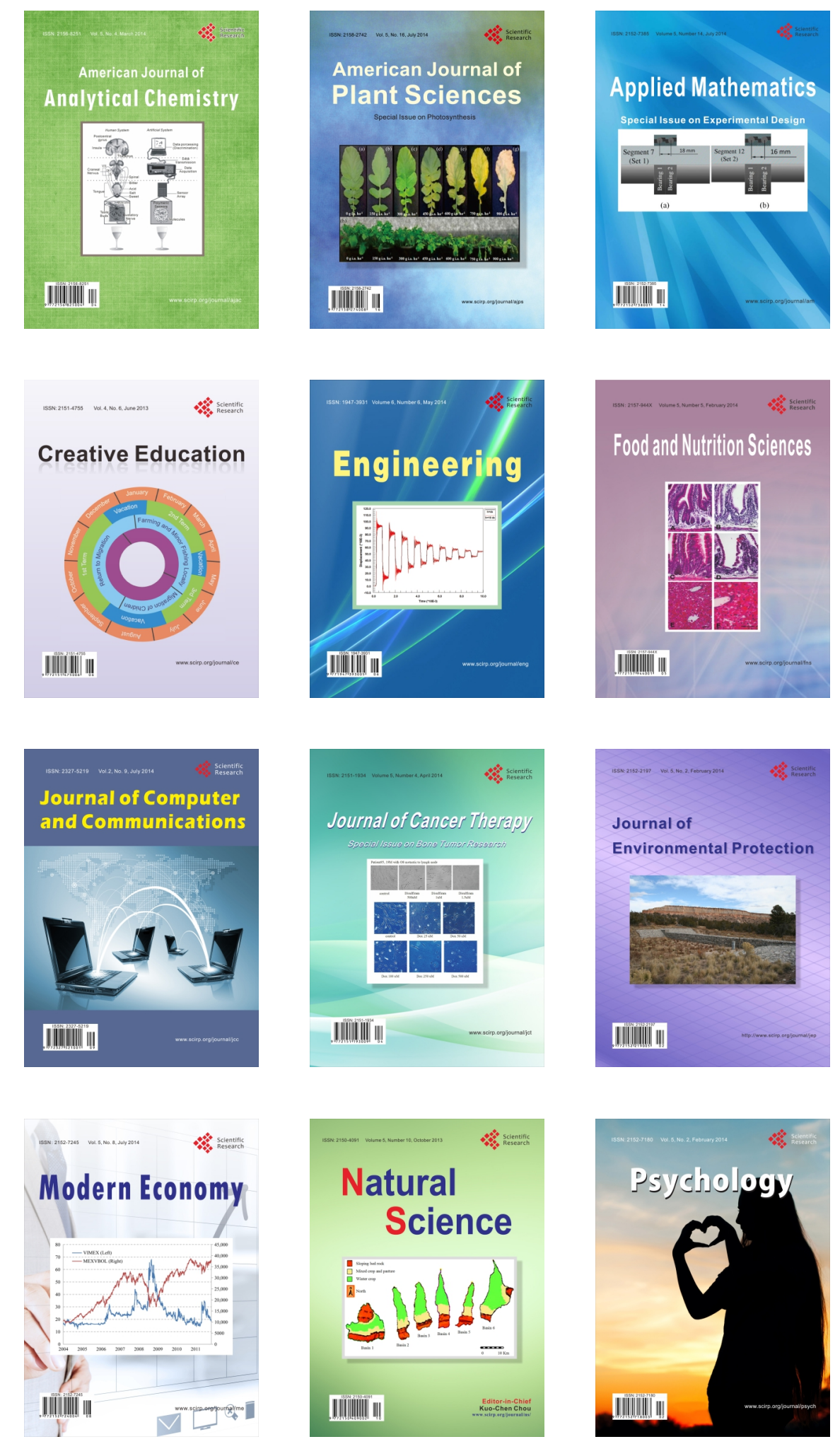